\title{
PSYCHIATRIC COMORBIDITY IN CHILDREN WITH ATTENTION-DEFICIT HYPERACTIVITY DISORDER
}

\author{
Harjot Singh1, Garg P. D², Kaur Kanwaljit ${ }^{3}$
}

1 Psychiatric Consultant, Department of Psychiatry, Dr. Harjot Singh Neuropsychiatric Center.

2 Psychiatric Consultant, Department of Psychiatry, Government Medical College, Amritsar.

3M. Phil, Department of Psychology.

\section{BACKGROUND}

\section{ABSTRACT}

The history of recognition of ADHD as a child psychiatric disorder spans more than a century. Early conceptualisations included both Neurological and Psychological notions of causation, which have evolved over time into models of the disorder that attempt to integrate knowledge of brain anatomy and function with behaviour.

Objective- The present study is being undertaken with the primary purpose of determining the psychiatric comorbidity among children and adolescents with ADHD less than 18 years of age, depending on age, sex and source of patient population.

\section{MATERIALS AND METHODS}

The sample included 50 children and adolescents under 18 years of age diagnosed as having ADHD. The diagnosis and the comorbidities will be made by the use of the rating scales- The Conners' Parent and Teacher Rating Scales, Childhood Psychopathology Measurement Schedule (CPMS) and the Child Behaviour Checklist (CBCL).

\section{RESULTS}

$74 \%$ of the cases out of a sample of 50 children with ADHD were found to have at least one psychiatric comorbidity. The most common psychiatric comorbidity in the ADHD cases was disruptive behaviour disorder (46\%); followed by anxiety disorder (20\%); affective disorder (18\%); mental retardation (18\%); enuresis (16\%); epilepsy (10\%); encopresis (6\%); tic disorder (6\%); autism (2\%); substance-related disorder (2\%) and other psychotic disorders were also found in $2 \%$ of the total cases.

\section{CONCLUSION}

According to our results, among the 50 cases of ADHD presented in the sample, almost all cases had at least one comorbid disorder and the pathophysiology was prevalent almost among all the groups. The advantages of following the practice of diagnosing comorbid psychiatric disorders is that it will promote research to focus on pathogenesis of these presentations and lead to development of specific strategies directed to treating them.

\section{KEYWORDS}

Attention-Deficit/Hyperactivity Disorder, Psychiatric Comorbidity, Children, Adolescents.

HOW TO CITE THIS ARTICLE: Singh H, Garg PD, Kanwaljit K. Psychiatric comorbidity in children with attention-deficit hyperactivity disorder. J. Evolution Med. Dent. Sci. 2017;6(95):6975-6981, DOI: 10.14260/jemds/2017/1514

\section{BACKGROUND}

The history of the recognition of ADHD as a child psychiatric disorder spans more than a century. Early conceptualisations included both neurological and psychological notions of causation, which have evolved over time into models of the disorder that attempt to integrate knowledge of brain anatomy and function with behaviour. ${ }^{1}$

Attention-deficit hyperactivity disorder (ADHD) occurs in all ages, but typically first appears in early childhood. Studies have stated that around half of children diagnosed as having ADHD continue to suffer the symptoms of this disorder in their adult life with significant impacts on their achievement level, sense of well-being ${ }^{2}$ and social status.

ADHD is believed to be the most common psychiatric disorder in children, affecting 3 to 5 percent of the school-age population. ${ }^{3}$ Males predominate the ratio with $2-3: 1$, for both clinic samples of children with ADHD and school-age children.

'Financial or Other Competing Interest': None.

Submission 25-10-2017, Peer Review 08-12-2017,

Acceptance 14-12-2017, Published 23-12-2017.

Corresponding Author:

Dr. Kaur Kanwaljit,

H. No. 96/B, Darshan Avenue,

G. T. Road Bypass, Amritsar.

E-mail: kanwaljitpsyche5@gmail.com

DOI: $10.14260 /$ jemds/2017/1514

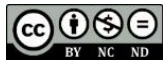

During the past few years, much research focused on the core deficits associated with the disorder, on the development of empirically tested diagnostic criteria, further validating the diagnosis of ADHD by demonstrating the disorder's characteristic symptom profiles, natural history, familygenetic aspects and response to treatment. The advantages of following the practice of diagnosing comorbid psychiatric disorders is that it will promote research to focus on pathogenesis of these presentations, and lead to development of specific strategies directed to treating them. ${ }^{4}$

The rates of comorbid conditions are estimated to be as high as $80 \% .^{5}$ The rates of comorbid conditions vary depending on age, sex, and the source of the patient population. The comorbidity rate of different disorders with ADHD including the mood disorders like major depression, bipolar disorder and dysthymia ranges from $19 \%$ to $37 \%$, for anxiety disorders it ranges from $25 \%$ to $50 \%$, for alcohol abuse $32 \%$ to $53 \%$, and for other types of substance abuse including marijuana and cocaine abuse, the comorbidity rate is $8 \%$ to $32 \%$. Comorbidity with personality disorders has been reported to be $10 \%$ to $20 \%$, and for learning disabilities it is $20 \% .^{6}$

\section{MATERIALS AND METHODS}

Subjects for the study involved children and adolescents, less than 18 years of age, visiting the Outpatient Department (OPD) 
of Neuropsychiatric Centre, Amritsar. A sample of 50 children was selected who had been diagnosed as having ADHD. The nature and purpose of the study was explained to the parent/guardian and they were assured about confidentiality of information given and an informed consent was taken. The sample thus selected was administered the proforma which consists of identification data, history taking and general physical examination. The diagnosis and the comorbidities was made by the use of the rating scales-the Conners' parent and teacher's rating scale, Childhood Psychopathology Measurement Schedule (CPMS), the Child Behaviour Checklist (CBCL).

\section{Study Design and Statistical Methods}

A cross-sectional study design was used to conduct the study. The data so generated was analysed as per standard statistical procedure using SPSS for Windows ${ }^{\mathrm{TM}}$ and testing for Chisquare.

\section{Method of Selection}

A sample of 50 children and adolescents under 18 years of age diagnosed as having ADHD on the basis of DSM-V criteria, irrespective of the severity of involvement was chosen from the Outpatient Department (OPD) of a Neuropsychiatric Centre, Amritsar. Consent of the parent/guardian was taken.

\section{Instruments and Scales}

The following Instruments and Scales were used on the Patients in the Present Study-

- Proforma for Identification, History taking and General Physical Examination: It consists of a proforma for detailed clinical and psychiatric assessment of the subjects.

- Conners' Rating Scale ${ }^{7}$ : The CRS developed by CK Conners' is a scale that evaluates a broad range of psychopathology and behavioural problems in children. The CRS-R is intended for use in children of 3 to 17 years of age. The CRS-R includes an Attention-Deficit Hyperactivity Disorder ADHD scale and a global index which is particularly useful for monitoring of change during treatment. The CRS-R has DSM IV scales which are directly linked to DSM V diagnostic criteria. Internal consistency coefficients for the CRS-R have been calculated elsewhere. Cronbach's alphas range from 0.77 to 0.95 , internal consistency coefficients for the subscales are also high.

A. Conners' Parent Rating Scale-Revised Version The CPRS-RS contains 27 items. It is typically used with parents or caregivers when information and DSM-V consideration is required.

- Childhood Psychopathology Measurement Schedule (CPMS): It is based upon the child behaviour checklist and was standardised on Indian children by Malhotra et al. The CPMS in its final form consists of 75 items, both in Hindi and English language to be rated on 2 points score " 0 " and " 1 " i.e. " 0 " for absent and " 1 " for present. It is applicable to children of both sexes in the age group of 4 14 years and more. It has been used as a screening instrument to identify disturbed children in the population. Children who score 10 or more are likely to be having psychopathology.

The different items are divided into 8 factors. The scores of items on each factor are summoned to give the total factor score. Those children who score 10 and above will be considered as having positive psychopathology.

\section{The different 8 Factors are-}

1. Low intelligence with behaviour problems.

2. Conduct disorder.

3. Anxiety.

4. Depression.

5. Psychotic symptoms.

6. Special symptoms.

7. Physical illness with emotional problems.

8. Somatisation.

It is in the form of interview schedule that can also be used as a self-administered questionnaire. These will be filled by the parents preferably mothers. The reliability and validity of the scale has been reported elsewhere and is thus satisfactory.

- Child Behaviour Checklist (CBCL): the CBCL, developed by TM Achenbach, is an assessment tool that is intended to be one part comprehensive, multi-informant evaluation of a child's behaviour. The CBCL/4-18 is a 113-item behavioural problems checklist with a seven-part social competency checklist. The CBCL has been tested in large populations and is fairly easy and brief to administer. It is used both in clinical settings and in research. The CBCL is the standard in the child psychopathology field against which other instruments are often measured.

\section{RESULTS}

According to the findings, out of 38 males, out of a sample of 50 children diagnosed with ADHD, 21, i.e., $55.3 \%$ fell into the combined sub-type, 10 (26.3\%) in the inattentive sub-type and 7 (18.4\%) fell in the Hyperactive/Impulsive sub-type of ADHD. Thus, the highest no. of males fell into the combined type, whereas an equal distribution of females was found both in the combined and inattentive subtypes. Among the age groups, 7 12 years of age group mostly had combined type of ADHD whereas, 13-18 years of age-group mostly had inattentive type of ADHD. The distribution of cases according to the diagnosis and sub-type of ADHD is given in Table I.

With regard to comorbidity, $74 \%$ children out of a sample of 50 had at least one psychiatric comorbidity. Males were found more in numbers than females in having comorbid disorder present other than ADHD. 78.9\% of males, i.e. 37 out of 50 had comorbidity present as compared to $58.3 \%$ of females. In the age-groups, children from 13-18 years of age had highest number in having comorbidities, i.e., $80.0 \%$ and among the subtypes the inattentive type were found to have higher number in having comorbidities. The comorbidity distribution according to age, sex and subtype is given in Table II. 


\begin{tabular}{|c|c|c|c|c|}
\hline & Combined Type & Inattentive Type & Hyperactive/ Impulsive type & Total \\
\hline Sex & $21(55.3 \%)$ & $10(26.3 \%)$ & $7(18.4 \%)$ & 38 \\
Males & $5(41.7 \%)$ & $5(41.7 \%)$ & $2(16.7 \%)$ & 12 \\
Females & $4(15.4 \%)$ & $0(0.0 \%)$ & $5(55.6 \%)$ & 9 \\
\hline Age-Groups & $18(69.2 \%)$ & $9(60.0 \%)$ & $4(44.4 \%)$ & 31 \\
$0-6$ & $4(15.4 \%)$ & $4(44.4 \%)$ & $0(0.0 \%)$ & 10 \\
$7-12$ & $13-18 \quad$ Table I. Characteristics of Cases According to the Diagnosis and Subtype of ADHD \\
\hline \multicolumn{4}{|c}{}
\end{tabular}

\begin{tabular}{|c|c|c|c|}
\hline & Absent & Present & Total \\
\hline $\begin{array}{l}\text { Sex } \\
\quad \text { Males } \\
\quad \text { Females }\end{array}$ & $\begin{array}{l}8(21.1 \%) \\
5(41.7 \%)\end{array}$ & $\begin{array}{c}30(78.9 \%) \\
7(58.3 \%)\end{array}$ & $\begin{array}{l}38 \\
12\end{array}$ \\
\hline $\begin{array}{c}\text { Age-Groups } \\
0-6 \\
7-12 \\
13-18\end{array}$ & $\begin{array}{l}3(33.3 \%) \\
8(25.8 \%) \\
2(20.0 \%)\end{array}$ & $\begin{array}{c}6(66.7 \%) \\
23(74.2 \%) \\
8(80.0 \%)\end{array}$ & $\begin{array}{c}9 \\
31 \\
10\end{array}$ \\
\hline $\begin{array}{l}\text { Subtype } \\
\text { Combined type } \\
\text { Inattentive type } \\
\text { Hyperactive/Impulsive type }\end{array}$ & $\begin{array}{l}6(23.1 \%) \\
3(20.0 \%) \\
4(44.4 \%)\end{array}$ & $\begin{array}{c}20(76.9 \%) \\
12(80.0 \%) \\
5(55.6 \%)\end{array}$ & $\begin{array}{l}26 \\
15 \\
9\end{array}$ \\
\hline
\end{tabular}

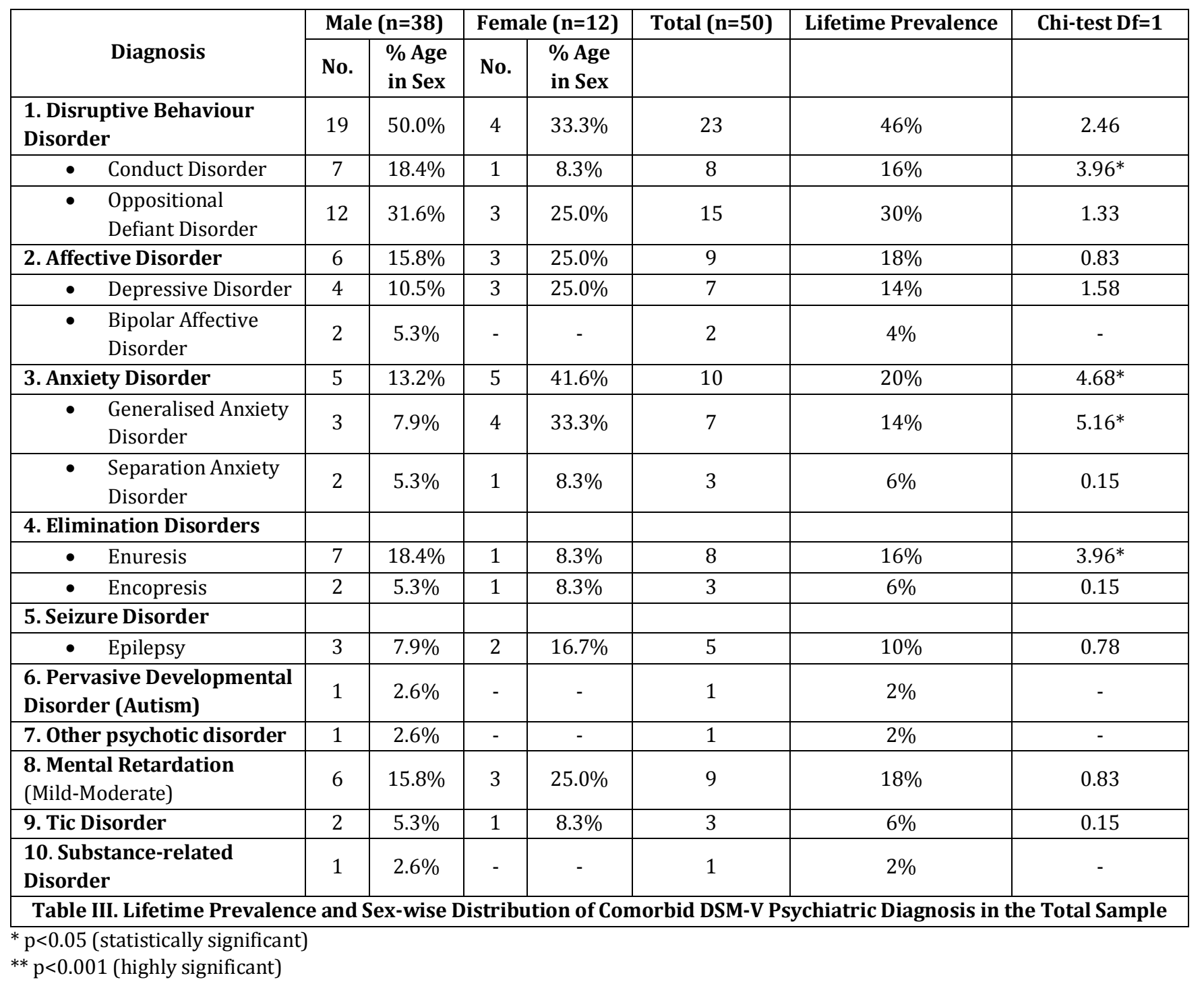




\begin{tabular}{|c|c|c|c|c|c|c|c|c|}
\hline \multirow{2}{*}{ DIAGNOSIS } & \multicolumn{2}{|c|}{$\begin{array}{c}\text { Combined Type } \\
(n=26)\end{array}$} & \multicolumn{2}{|c|}{$\begin{array}{l}\text { Inattentive Type } \\
(n=15)\end{array}$} & \multicolumn{2}{|c|}{$\begin{array}{c}\text { Hyperactive- } \\
\text { Impulsive Type }(n=9)\end{array}$} & \multirow{2}{*}{ Total } & \multirow{2}{*}{$\begin{array}{c}\text { Chi-test } \\
\mathrm{Df}=2\end{array}$} \\
\hline & No. & $\begin{array}{c}\text { \% Age in } \\
\text { Combined Type }\end{array}$ & No. & $\begin{array}{c}\text { \% Age in } \\
\text { Inattentive Type }\end{array}$ & No. & $\begin{array}{l}\text { \% Age in } \\
\text { H-I Type }\end{array}$ & & \\
\hline $\begin{array}{l}\text { 1. Disruptive Behaviour } \\
\text { Disorder }\end{array}$ & 16 & $61.5 \%$ & 4 & $26.6 \%$ & 3 & $33.3 \%$ & 23 & $6.24^{*}$ \\
\hline • $\quad$ Conduct Disorder & 5 & $19.2 \%$ & 1 & $6.7 \%$ & 2 & $22.2 \%$ & 8 & 1.67 \\
\hline $\begin{array}{ll}\bullet & \text { Oppositional } \\
& \text { Defiant Disorder }\end{array}$ & 11 & $42.3 \%$ & 3 & $20.0 \%$ & 1 & $11.1 \%$ & 15 & $14.2^{*}$ \\
\hline 2. Affective Disorder & 4 & $15.4 \%$ & 5 & $33.3 \%$ & - & - & 9 & $6.48^{*}$ \\
\hline • $\quad$ Depressive Disorder & 2 & $7.7 \%$ & 5 & $33.3 \%$ & - & - & 7 & $7.29 *$ \\
\hline $\begin{array}{ll}\bullet & \text { Bipolar Affective } \\
& \text { Disorder } \\
\end{array}$ & 2 & $7.7 \%$ & - & - & - & - & 2 & - \\
\hline 3. Anxiety Disorder & 3 & $11.5 \%$ & 6 & $40.0 \%$ & 1 & $11.1 \%$ & 10 & $6.35^{*}$ \\
\hline $\begin{array}{ll} & \text { Generalised Anxiety } \\
& \text { Disorder }\end{array}$ & 2 & $7.7 \%$ & 5 & $33.3 \%$ & - & - & 7 & $7.29 *$ \\
\hline $\begin{array}{ll} & \text { Separation Anxiety } \\
& \text { Disorder }\end{array}$ & 1 & $3.8 \%$ & 1 & $6.7 \%$ & 1 & $11.1 \%$ & 3 & 0.64 \\
\hline \multicolumn{9}{|l|}{ 4. Elimination Disorders } \\
\hline$\bullet \quad$ Enuresis & 5 & $19.2 \%$ & 1 & $6.7 \%$ & 2 & $22.2 \%$ & 8 & 1.67 \\
\hline - $\quad$ Encopresis & 2 & $7.7 \%$ & 0 & & 1 & $11.1 \%$ & 3 & 4.23 \\
\hline \multicolumn{9}{|l|}{ 5. Seizure Disorder } \\
\hline • $\quad$ Epilepsy & 3 & $11.5 \%$ & 1 & $6.7 \%$ & 1 & $11.1 \%$ & 5 & 0.27 \\
\hline $\begin{array}{l}\text { 6. Pervasive Developmental } \\
\text { Disorder (Autism) }\end{array}$ & 1 & $3.84 \%$ & - & - & - & 21010 & 1 & - \\
\hline 7. Other psychotic disorder & 1 & $3.84 \%$ & - & - & - & - & 1 & - \\
\hline $\begin{array}{l}\text { 8. Mental Retardation } \\
\text { (Mild-Moderate) }\end{array}$ & 5 & $19.2 \%$ & 2 & $13.3 \%$ & 2 & $22.2 \%$ & 9 & 0.64 \\
\hline 9. Tic Disorder & 2 & $7.7 \%$ & 1 & $6.7 \%$ & - & -- & 3 & 0.43 \\
\hline $\begin{array}{l}\text { 10. Substance-related } \\
\text { Disorder }\end{array}$ & 1 & $3.84 \%$ & - & & - & -- & 1 & - \\
\hline
\end{tabular}

${ }^{*} \mathrm{p}<0.05$ (statistically significant), ${ }^{* *} \mathrm{p}<0.001$ (highly significant)

\begin{tabular}{|c|c|c|c|c|c|c|c|c|}
\hline \multirow[b]{2}{*}{ DIAGNOSIS } & \multicolumn{2}{|r|}{$0-6(n=9)$} & \multicolumn{2}{|r|}{$7-12(n=31)$} & \multicolumn{2}{|r|}{$13-18(n=10)$} & \multirow[b]{2}{*}{ Total } & \multirow[b]{2}{*}{$\begin{array}{l}\text { Chi- } \\
\text { test } \\
\text { Df=2 }\end{array}$} \\
\hline & No. & $\begin{array}{c}\text { \% Age in 0-6 } \\
\text { years Age } \\
\text { Group }\end{array}$ & No. & $\begin{array}{c}\text { \% Age in 7-12 } \\
\text { years Age } \\
\text { Group }\end{array}$ & No. & $\begin{array}{c}\text { \% Age in 13-18 } \\
\text { years Age } \\
\text { Group }\end{array}$ & & \\
\hline $\begin{array}{l}\text { 1. Disruptive Behaviour } \\
\text { Disorder }\end{array}$ & 3 & $33.3 \%$ & 16 & $51.7 \%$ & 4 & $40.0 \%$ & 23 & 1.83 \\
\hline • Conduct Disorder & 1 & $11.1 \%$ & 6 & $19.4 \%$ & 1 & $10.0 \%$ & 8 & 1.68 \\
\hline $\begin{array}{ll}\text { - Oppositional Defiant } \\
\text { Disorder }\end{array}$ & 2 & $22.2 \%$ & 10 & $32.3 \%$ & 3 & $30.0 \%$ & 15 & 0.34 \\
\hline 2. Affective Disorder & & & 6 & $19.3 \%$ & 3 & $30.0 \%$ & 9 & 4.46 \\
\hline • Depressive Disorder & - & - & 5 & $16.1 \%$ & 2 & $20.0 \%$ & 7 & 1.88 \\
\hline $\begin{array}{ll} & \text { Bipolar Affective } \\
& \text { Disorder }\end{array}$ & - & - & 1 & $3.2 \%$ & 1 & $10.0 \%$ & 2 & 1.36 \\
\hline 3. Anxiety Disorder & 2 & $22.2 \%$ & 5 & $16.1 \%$ & 3 & $30.0 \%$ & 10 & 0.03 \\
\hline $\begin{array}{ll} & \text { Generalised Anxiety } \\
& \text { Disorder }\end{array}$ & - & & 4 & $12.9 \%$ & 3 & $30.0 \%$ & 7 & 1.88 \\
\hline $\begin{array}{ll}\text { - } & \text { Separation Anxiety } \\
& \text { Disorder } \\
\end{array}$ & 2 & $22.2 \%$ & 1 & $3.2 \%$ & - & - & 3 & $6.12^{*}$ \\
\hline \multicolumn{9}{|l|}{ 4. Elimination Disorders } \\
\hline$\bullet \quad$ Enuresis & 1 & $11.1 \%$ & 6 & $19.3 \%$ & 1 & $10.0 \%$ & 8 & 1.68 \\
\hline - $\quad$ Encopresis & 1 & $11.1 \%$ & 2 & $6.5 \%$ & - & & 3 & 1.06 \\
\hline \multicolumn{9}{|l|}{ 5. Seizure Disorder } \\
\hline • $\quad$ Epilepsy & 1 & $11.1 \%$ & 3 & $9.7 \%$ & 1 & $10.0 \%$ & 5 & 0.08 \\
\hline $\begin{array}{l}\text { 6. Pervasive Developmental } \\
\text { Disorder (Autism) }\end{array}$ & 1 & $11.1 \%$ & - & - & - & - & 1 & - \\
\hline 7. Other psychotic disorder & -- & - & 1 & $3.2 \%$ & - & - & 1 & - \\
\hline $\begin{array}{l}\text { 8. Mental Retardation (Mild- } \\
\text { Moderate) }\end{array}$ & 3 & $33.3 \%$ & 5 & $16.1 \%$ & 1 & $10.0 \%$ & 9 & \\
\hline 9. Tic Disorder & - & & 2 & $6.5 \%$ & 1 & $10.0 \%$ & 3 & 0.87 \\
\hline 10. Substance-related Disorder & - & & - & & 1 & $10.0 \%$ & 2 & - \\
\hline
\end{tabular}

${ }^{*} \mathrm{p}<0.05$ (statistically significant), ${ }^{* *} \mathrm{p}<0.001$ (highly significant) 


\section{DISCUSSION}

Attention Deficit Hyperactivity Disorder (ADHD) is a neurodevelopmental disorder which affects between three to five percent of all school aged children ${ }^{8,9}$ and is characterised by excessive levels of hyperactivity, inattention and impulsivity. ADHD and its comorbidities have a negative impact on peer and family relations, as well as poor academic performance, which means that ADHD has a detrimental effect on individuals, their families and society as a whole.

The present study was undertaken with the primary purpose of determining the psychiatric comorbidity in a sample of 50 children and adolescents with ADHD aged less than 18 years.

In the present study, combined group was the largest group with $52 \%$ patients, followed by inattentive group with $30 \%$ patients and hyperactive-impulsive group had 18\% patients. This prevalence pattern (subtype-wise) amongst children with ADHD has been consistent with the results of some earlier researches $10,11,12,13$ and also with the study of Spencer et al who after reviewing literature had found the combined type to be the most common subtype followed by inattentive subtype and hyperactive subtype. Some other studies ${ }^{14,15}$ have tended to differ on the subtype differentiation, this could be due to the randomised sample included in their studies and difference in criteria used for categorisation and younger age groups considered in those studies.

Subtype differentiation had no statistically significant association with the presence of psychiatric comorbidity in the sample. The commonest disorders found in the study were disruptive behaviour disorders, followed by anxiety disorders, affective disorders, mental retardation, elimination disorders, seizure disorder, substance-related disorders and other psychotic disorders were least common. This finding was consistent with the views of Spencer et al, who after reviewing the literature, had come to the conclusion that most studies irrespective of the sample and the methodology, support the presence of an increased prevalence of behavioural and emotional disorders in ADHD. These problems lead to impairment in functioning, poor school performance, behaviour problems and are often the reasons for referral to clinics.

In the study, $66.7 \%$ cases of $0-6$ years age group had comorbid psychiatric disorder, $74.2 \%$ children of age group of 7-12 years and $80.0 \%$ adolescents of 13-18 years age group had comorbidity present.

In the present study, majority of the sample (76\%) were males and $24 \%$ were females. This may be due to the randomised sample included in the study and it is in accordance with the sex wise distribution of the ADHD sample included in previous studies in India and abroad. Comorbidity has been found to be present more in males (78.9\%) than in females $(58.3 \%)$.

Literature has revealed that the symptoms of ADHD decline with age and that the decline is maximum in the older age groups. ${ }^{16}$ Applying the Conners' Rating Scale-Revised, it was found that the hyperactivity decreased with age and the features of inattention increased with age. These results were in accordance with the results of previous studies ${ }^{17}$ and could possibly be due to the fact that with increasing age the demands for attention too are increased and inattention becomes evident.18 Boys were rated higher on all the subscales, namely hyperactivity, inattention, ODD and Conners' ADHD index in comparison to girls, the difference was statistically significant for hyperactivity, ODD and ADHD index. This could possibly be due to the fact that boys display more features of hyperactivity and aggressive behaviour than girls. 19,20

Children in whom comorbidity was present displayed more features of hyperactivity, impulsiveness, oppositional defiance and inattention than do children without comorbidity, which could be because of the added burden of comorbidity in an already compromised child. Comparison of the Conners' Parent and Teacher Rating Scale showed that parents had rated their children higher than the teachers did, which could be due to the fact that the parents are not exposed to a large number of children while the teachers rate the child in comparison to other children.

When comorbidity is present, there is a statistically significant association for the presence of problems in activities and total competence which could be due to the impact of comorbidity on social behaviour, inadequate social skills, impulsivity in children with ADHD which further worsens with the presence of comorbidity, lack of social support system from family and friends, frequent taunts, teasing, exclusion and exploitation (Spencer et al).

Conduct disorder using CPMS while rule breaking behaviour, aggression and externalising problems using CBCL were present significantly more in combined subgroup than in the inattentive subgroup and hyperactive subgroup on rulebreaking behaviour. The presence of conduct, rule breaking behaviour and externalising disorders has been studied in previous studies as well with comparable results with the cases having combined type of ADHD displaying more aggressive behaviour and having more conduct and externalising problems than inattentive and hyperactiveimpulsive type. 21,22

When psychiatric comorbidity is present in ADHD, there is statistically significant association for the presence of conduct disorder (using CPMS), rule breaking behaviour, aggression and externalising problems (using CBCL) which could be due to the impact of comorbidity on ADHD which can further decrease self-control, increase impulsivity, due to various environmental and social factors as poor frustration tolerance, inability to communicate, poor coping skills, neglect, exploitation, work stress, poor adaptability to environment or these behaviour problems could be the manifestation of comorbid psychiatric illness.

There are important nosologic distinctions between ADHD and that of associated symptoms common to the disruptive behaviour disorder. ODD is characterised by a pattern of negativistic, hostile and defiant behaviour. In the present study, oppositional defiant disorder was found in $30 \%$ of the children. Combined type had significantly more cases of oppositional defiant disorder than both inattentive and hyperactive-impulsive type

Using Conners' Rating Scale, it was found that the rates of oppositional defiant disorder was more in cases in which some comorbidity was present. The current prevalence of enuresis is $16 \%$ and of encopresis is $6 \%$ in the present sample and amongst the combined type it was the highest. The results are in comparison with those of earlier studies in which children with ADHD have shown similar rates of enuresis and encopresis. ${ }^{23,24}$ 
Learning problems, social skills deficits and low selfesteem are often associated with ADHD and represents risk factor for development of mood disorders and could possibly lead to the occurrence of affective symptoms. Results of the present study have revealed that prevalence of mood disorders is $18 \%$ in comparison to $11.4 \%$ and $14.3 \%$ prevalence in two previous studies. Comorbid mood disorders in the present study were, depression, constituting $14 \%$ and bipolar affective disorder $4 \%$. The results are in concordance with a review study and studies done in India (Mukhopadhaya et al) and those done abroad (Byun et al). The results; however, were not comparable with other studies which reported a higher rate of mood disorders.

Childhood anxiety disorders are often not suspected in an overactive child, but when present, they contribute to further social, behaviour and academic dysfunction. In the present sample, prevalence of DSM-V diagnosis of anxiety disorders was $20 \%$ as compared to $29.7 \%$ in a previous Indian study and $24.2 \%$ and $33.3 \%$ in studies done abroad.

In the present study, only one case (2\%) fulfilled the criteria for other psychotic disorders and no case in the sample fulfilled the criteria for schizophrenia. This is comparable to presence of $1 \%$ of other psychotic disorders in a recently conducted American study (Biederman et al). Using CBCL, it was found that the combined type had significantly more thought problems than the other two groups and when comorbidity was present, it was associated with the presence of significantly more thought problems. The results are in concordance with a previous study (Byun et al).

In the present study, physical illness with emotional symptoms (using CPMS) were statistically more common in the combined type, and other symptoms (using CBCL) were also more common in combined type and when psychiatric comorbidity was present.

In the present study, attention problems are more in the inattentive type followed by combined type and hyperactiveimpulsive type. This could be due to increasing impairments in cognitive performance with subtype differentiation and is in accordance with the results of a previous study. When comorbidity is present, there is a higher presence of attention problems which is statistically significant. It could be due to further impairment in already compromised concentration ability and cognitive performance in ADHD, or could be due to the manifestation of comorbidity as in mood disorders and anxiety disorders.

Thus, when comorbidity is present, there is statistically significant association for the presence of low intelligence with behaviour problems on CPMS and higher scores of total behaviour problems on CBCL. The presence of comorbidity in ADHD can further impair child's communication skills, cognitive performance and adaptability to environment, which in turn can act as a stress factor for behaviour problems.

\section{CONCLUSION}

According to our results, among the 50 cases of ADHD presented in the sample, almost all cases had at least one comorbid disorder and the pathophysiology was prevalent almost among all the groups. The advantages of following the practice of diagnosing comorbid psychiatric disorders is that it will promote research to focus on pathogenesis of these presentations and lead to development of specific strategies directed to treating them.

\section{REFERENCES}

[1] McCracken JT. Attention-deficit/hyperactivity disorder. History. In: Kaplan HI, Saddock BJ. eds. Comprehensive Textbook of Psychiatry. Baltimore: Williams and Wilkins 2000;2(7):2679.

[2] Tamam L, Tuglu C, Karatas G, et al. Adult attentiondeficit hyperactivity disorder in patients with bipolar I disorder in remission: preliminary study. Psychiatry Clin Neurosci 2006;60(4):480-5.

[3] Hechtman L. Assessment and diagnosis of attentiondeficit/ hyperactivity disorder. Child Adolesc Psychiatr Clin N Am 2000;9(3):481-98.

[4] Grimaji SR, Biju ST, Srinath S, et al. Co-morbid psychiatric disorders in pervasive development disorders. JIACAM 1(2):45-51. Article 7.

[5] Biederman J, Faraone SV, Spencer T, et al. Patterns of psychiatric comorbidity, cognition and psychosocial functioning in adults with attention deficit/hyperactivity disorder. Am J Psychiatry 1993;150(12):1792-8.

[6] Murphy K, Barkley RA. Attention-deficit/hyperactivity disorder adults: comorbidities and adaptive impairments. Compr Psychiatry 1996;37(6):393-401.

[7] Conners CK. Normative samples and psychometric properties of the CRS-RTM-Age and sex effects. In Conners' Rating Scale-Revised Technical manual. Toronto. MHS Publications 2007;1(7):97.

[8] Buitelaar K. Epidemiology of attention deficit/hyperactivity disorder: What have we learned over the past decade? In: Sandberg S. edr. Hyperactivity disorders. Cambridge, UK: Cambridge University Press 2002:30-63.

[9] Spencer TJ, Biederman J, Mick E. Attention deficit/hyperactivity disorder: diagnosis, lifespan, comorbidities and neurobiology. Journal of Pediatric Psychology 2007;32(6):631-42.

[10] Lahey BB, Applegate B, McBurnett K, et al. DSM-IV field trials for attention deficit hyperactivity disorder in children and adolescents. Am J Psychiatry 1994;151(11):1673-85.

[11] Faraone SV, Biederman J, Mick E, et al. Family study of girls with attention deficit hyperactivity disorder. Am J Psychiatry 2000;157(7):1077-83.

[12] Byun H, Yang J, Lee M, et al. Psychiatric comorbidity in Korean children and adolescents with attention-deficit hyperactivity disorder: psychopathology according to the subtype. Yonsei Med Journal 2006;47(1):113-21.

[13] Gonzalez-Heydrich J, Dodds A, Whitney J, et al. Psychiatric disorders and behavioral characteristics of pediatric patients with both epilepsy and attentiondeficit hyperactivity disorder. Epilepsy Behav 2007;10(3):384-8.

[14] Bhatia MS, Choudhary S, Sidana A. Attention deficit hyperactivity disorder among psychiatric outpatients. Indian Pediatrics 1999;36(6):583-7.

[15] Busch B, Biederman J, Cohen LG, et al. Correlates of ADHD among children in pediatric and psychiatric clinics. Psychiatric Services 2002;53(9):1103-11.

[16] Biederman J, Mick E, Faraone SV. Age-dependent decline of symptoms of attention deficit hyperactivity disorder: impact of remission definition and symptom type. Am J Psychiatry 2000;157(5):816-8. 
[17] Conners CK. Normative samples and psychometric properties of the CRS-RTM-Age and sex effects. In Conners' Rating Scale-Revised Technical Manual. Toronto: MHS Publications 2007:97-105.

[18] Nolan EE, Volpe RJ, Gadow KD, et al. Developmental, gender comorbidity differences in clinically referred children with ADHD. Journal of Emotional and Behavioral Disorders 1999;7(1):11-20.

[19] Wilens TE, Biederman J, Spencer TJ, et al. Overview and neurobiology of attention deficit/ hyperactivity disorder. J Clin Psychiatry 2003;63(12):3-9.

[20] Derks EM, Dolan CV, Hudziak JJ, et al. Assessment and etiology of attention deficit hyperactivity disorder and oppositional defiant disorder in boys and girls. Behav Genet 2007;37(4):559-66.
[21] Eiraldi RB, Power TJ, Nezu CM. Patterns of comorbidity associated with subtypes of attentiondeficit/hyperactivity disorder among 6- to 12-year-old children. J Am Acad Child Adolesc Psychiatry 1997;36(4):503-14.

[22] Malhi P, Singhi P. Spectrum of attention deficit hyperactivity disorders in children among referrals to psychology services. Indian Pediatrics 2000;37(11): 1256-60.

[23] Biederman J, Mick E, Faraone SV, et al. Influence of gender on attention deficit hyperactivity disorder in children referred to a psychiatric clinic. Am J Psychiatry 2002;159(1):36-42.

[24] Mukhopadhyay M, Misra S, Mitra T, et al. Attention deficit hyperactivity disorder. Indian J Pediatr 2003;70(10):789-92. 